\title{
Influence of resin coating materials on Porphyromonas gingivalis attachment
}

\author{
Ai KUMADA ${ }^{1}$, Yoshizo MATSUKA ${ }^{1}$, Atsushi MINE¹, Mitsuaki ONO ${ }^{1}$, Junji UEHARA¹, Norihiro SONOI², Takashi ITO², \\ Shogo TAKASHIBA ${ }^{2}$ and Takuo KUBOKI ${ }^{1}$
}

\author{
${ }^{1}$ Department of Oral Rehabilitation and Regenerative Medicine, Okayama University Graduate School of Medicine, Dentistry and Pharmaceutical \\ Sciences, 2-5-1 Shikata-cho, Kita-ku, Okayama, 700-8525, Japan \\ ${ }^{2}$ Department of Pathophysiology-Periodontal Science, Okayama University Graduate School of Medicine, Dentistry and Pharmaceutical Sciences, \\ 2-5-1 Shikata-cho, Kita-ku, Okayama, 700-8525, Japan \\ Corresponding author, Takuo KUBOKl; E-mail: kuboki@md.okayama-u.ac.jp
}

\begin{abstract}
Resin coating materials have been used for composite resin or provisional restoration in order to prevent plaque accumulation on their surfaces. However, it is not clear whether the coating materials influence attachment of periodontal bacteria. Therefore, we investigated the effect of resin coating materials on the attachment of Porphyromonas gingivalis (Pg). The polymerized auto cure resin plates were coated with two resin coating materials. To estimate the Pg attachment, each plate was immersed in brain heart infusion medium containing Pg. The quantity of bacteria attached on each plate was evaluated by crystal violet quantification. Morphological change of Pg was recorded using scanning electron microscopy. Both coating groups presented significantly lower Pg attachment compared to the control. The Pg shapes on the plates with resin coating materials were similar to the non-treated control plates. The resin coating materials clearly prevent Pg attachment on the polymerized auto cure resin plate.
\end{abstract}

Keywords: Resin coating material, Provisional restoration, Porphyromonas gingivalis (Pg), Bacteria attachment, Resin surface

\section{INTRODUCTION}

Dental plaque is closely associated with the pathogenesis of dental caries and periodontal diseases ${ }^{1)}$. According to some estimates, approximately 50\% of direct tooth restorations are replacements ${ }^{2}$, which emphasizes the clinical relevance of bacterial adherence to dental restorations ${ }^{3)}$. Composite resin filling of teeth or provisional restoration is essential to maintain aesthetics, provide masticating surfaces and protect the hard and soft tissues during the treatment. Recently, resin coating materials have become widely used for coating of composite resin filling or provisional restorations in order to prevent plaque accumulation. Some studies have shown that bonding resin or liquid polish coating reduces biofilm formation ${ }^{4)}$, Candida albicans attachment ${ }^{5)}$ and adhesion of Streptcoccus mutans $^{6}$.

Microbiological adhesion testing has primarily focused on restorative materials such as amalgam, glassionomers, and composite resins ${ }^{7-9)}$. Investigations regarding the bacterial adhesion to provisional fixed prosthodontic materials are limited ${ }^{10,11)}$. It has been reported that dental plaque adherence to teeth with provisional restorations is increased compared to natural teeth ${ }^{12)}$ and in some clinical cases, provisional restoration causes problems such as gingival inflammation ${ }^{13)}$.

However, there is no evidence available that can show whether the resin coating materials influence the effects of provisional restoration on periodontal bacteria. Porphyromonas gingivalis (Pg) is one of the most probable pathogens underlying the development of periodontal disease. Investigating the effects on coating

The first two authors contributed equally to this work.

Color figures can be viewed in the online issue, which is available at J-STAGE.

Received Jul 28, 2011: Accepted Sep 20, 2011

doi:10.4012/dmj.2011-164 JOI JST.JSTAGE/dmj/2011-164 materials on Pg adherence is useful for understanding their function in vitro. Therefore, the aim of this study was to investigate the effect of the commercially available resin coating materials on $\mathrm{Pg}$ attachment. The null hypotheses tested in this study were (1) that the resin coating material does not affect $\mathrm{Pg}$ attachment on resin plates after incubation with $\mathrm{Pg}$, and (2) that the Pg shape on the resin coated plates, as characterized by SEM examination, does not differ from that of the control.

\section{MATERIALS AND METHODS}

Resin plate and resin coating materials

Fifty-four round polymerized resin plates (diameter: 14 $\mathrm{mm}$, thickness: $2 \mathrm{~mm}$ ) were made with auto cure resin (poly(methylmethacrylate): methylmethacrylate $=1: 2$ ) (UNIFAST II, GC, Tokyo, Japan) (Fig. 1). The plates were polished using a 600-grit silicon carbide waterproof abrasive paper under running water. Each resin plate was sterilized for $3 \mathrm{~h}$ in an ultraviolet sterilizer (Telstar Bio-II-A/P, Terrassa, Spain). Then the plates were randomly divided into 3 groups (control and two resin coating groups; Coat-A: G-Coat, GC, Coat-B: Surface Coat, Kuraray Medical) (Table 1). After applying the coating material on each resin plate, the plate was air dried and irradiated with a halogen type irradiator (400-515 nm, $550 \mathrm{~mW} / \mathrm{cm}^{2}$ ) (Hyper Lightel DPC-120, Kuraray Medical, Tokyo, Japan). We irradiated 6 times on each plate to cure the coating materials uniformly ( $20 \mathrm{~s} \times 6$ times). The distance between the plate and irradiator was $5 \mathrm{~mm}$. Thereafter, the plate was wiped with $70 \%$ alcohol (Fig. 1).

Porphyromonas gingivalis attachment to the resin plates To estimate the antibacterial effect of the resins, each 
plate was immersed in brain heart infusion (BHI) medium (Nissui Pharmaceutical, Tokyo, Japan) containing Porphyromonas gingivalis W83 (Pg) $\left(1 \times 10^{6}\right.$ $\mathrm{CFU} / \mathrm{mL})$ at $37^{\circ} \mathrm{C}$ under anaerobic conditions $\left(80 \% \mathrm{~N}_{2}\right.$, $10 \% \mathrm{H}_{2}, 10 \% \mathrm{CO}_{2}$ ) for 12,24 or $36 \mathrm{~h}$ (Fig. 2). Each plate was subsequently washed with distilled water and incubated with $300 \mu \mathrm{L}$ of $0.1 \%$ crystal violet (Katayama Chemical, Osaka, Japan) at room temperature for $15 \mathrm{~min}$. The Crystal Violet stain was extracted from Pg with $560 \mu \mathrm{L}$ of $99 \%$ ethanol, and the solution absorbance was measured at $570 \mathrm{~nm}$ (Model 680 Microplate Reader, Bio-Rad Laboratories, Hercules, CA, USA).

The results are presented as the means \pm standard error of mean. Differences between the groups were evaluated by two-way analysis of variance (ANOVA) and a post hoc multi-comparisons test (Tukey-Kramer test) with two predictors; coating difference (coating materials/

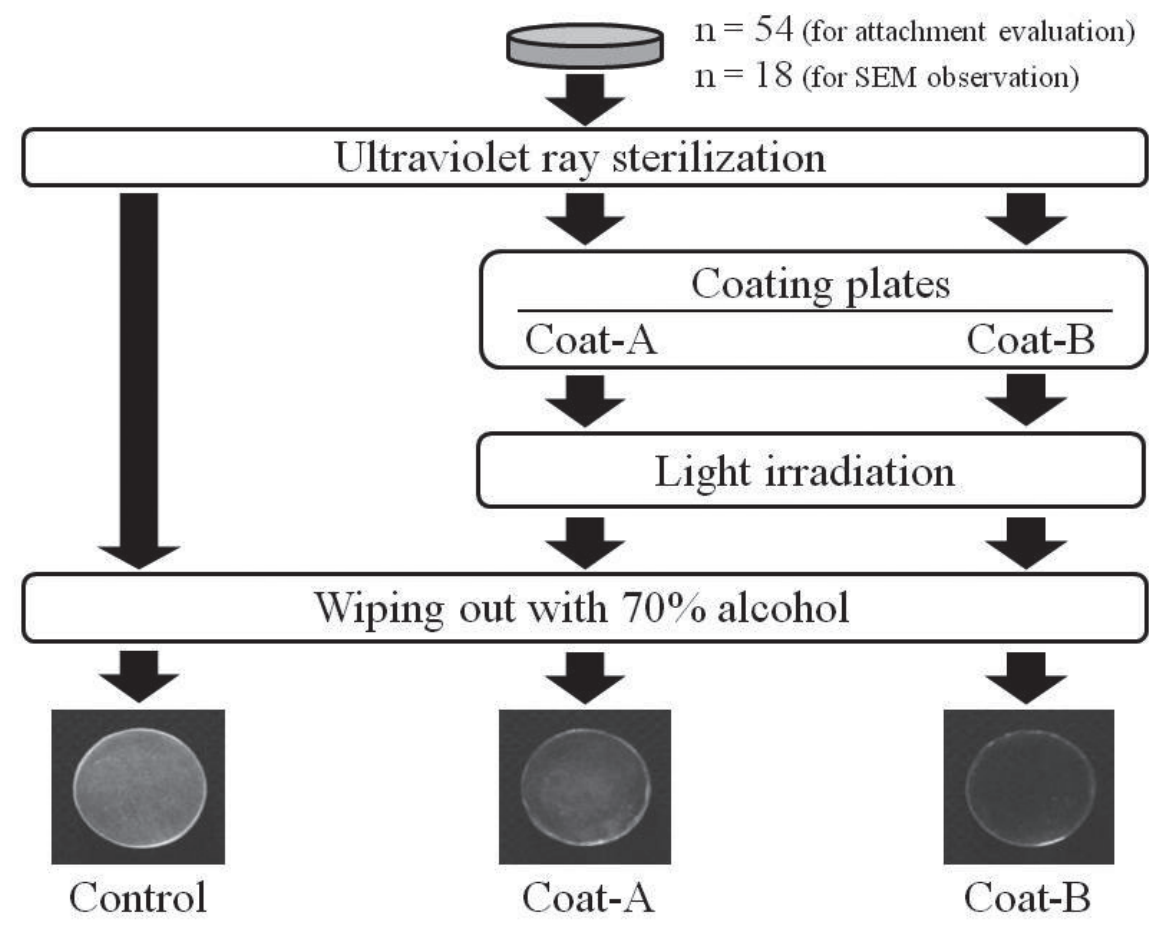

Fig. 1 Procedure for coating the resin plates.

Each resin plate was sterilized in an ultraviolet sterilizer for $3 \mathrm{~h}$ before coating. After applying the coating material on each resin plate, the plate was air dried and irradiated with a halogen type dental irradiator $\left(400-515 \mathrm{~nm}, 550 \mathrm{~mW} / \mathrm{cm}^{2}, 20 \mathrm{~s} \times 6\right.$ times). Then the plate was wiped with $70 \%$ alcohol.

Table 1 Resin plate and resin coating materials

\begin{tabular}{ll}
\hline Material used & powder \\
$\begin{array}{l}\text { UNIFAST II } \\
\text { (Cont., GC) }\end{array}$ & $\begin{array}{l}\text { ethyl-methyl copolymer } \\
\text { polymethylmethacrylate } \\
1 \text {-cyclohexyl-5-ethyl barbituric acid } \\
\text { acetylacetone copper } \\
\text { methyl methacrylate } \\
\text { ethyleneglycol dimethaclylate } \\
\text { dilauryl dimethyl ammonium chloride }\end{array}$ \\
$\begin{array}{l}\text { Coat-A } \\
\text { (G-COAT, GC) }\end{array}$ & $\begin{array}{l}\text { silica filler } \\
\text { methylmethacrylate } \\
\text { multifunctional methacrylate } \\
\text { phosphoric ester monomer } \\
\text { photo initiator }\end{array}$ \\
$\begin{array}{l}\text { Coat-B } \\
\text { (SURFACE COAT, }\end{array}$ & $\begin{array}{l}\text { methylmethacrylate } \\
\text { aliphatic hexaacrylate } \\
\text { Kuraray Medical) }\end{array}$ \\
\hline
\end{tabular}



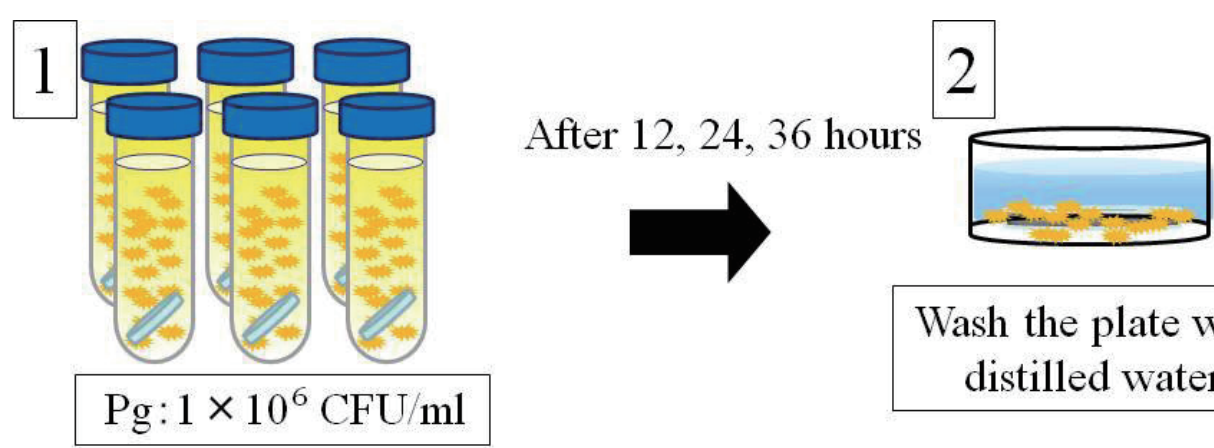

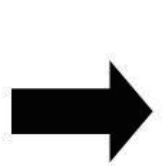

3

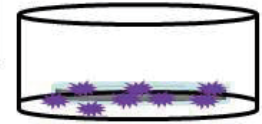

Stain Pg with Crystal Violet

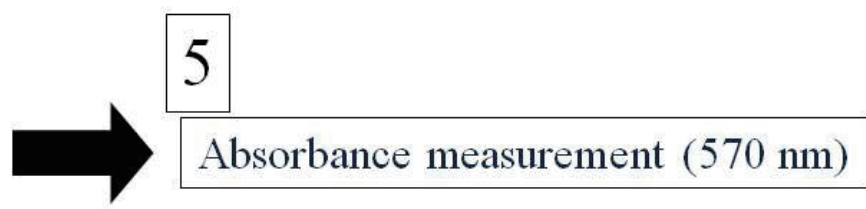

\section{Wash the plate with} distilled water

Fig. 2 Evaluation of Porphyromonas gingivalis attachment.

Each plate was immersed in Brain Heart Infusion medium containing Pg $\left(1 \times 10^{6} \mathrm{CFU} / \mathrm{mL}\right)$ at $37^{\circ} \mathrm{C}$ under anaerobic conditions $\left(80 \% \mathrm{~N}_{2}, 10 \% \mathrm{H}_{2}, 10 \% \mathrm{CO}_{2}\right)$ for 12,24 or $36 \mathrm{~h}$. Each plate was then washed with distilled water and incubated with $0.1 \%$ Crystal Violet. The Crystal Violet stain was taken off with $99 \%$ ethanol and the solution absorbance was measured at $570 \mathrm{~nm}$.

control) and incubation time, using the Stat View 4.0 software program (Abacus Concepts, Inc., Berkley, CA, USA).

\section{Scanning electron microscopy evaluation}

Six resin plates for each group were prepared in the same way as for the $\mathrm{Pg}$ attachment testing and each plate was immersed in BHI medium containing Pg for 36 h. The Pg shape was recorded with a scanning electron microscope (SEM: DS-720, Topcon Corp, Tokyo, Japan). The attached $\mathrm{Pg}$ on each plate was fixed with $1 \%$ formaldehyde and 1\% osmium tetroxide for 15 min each. Next, the resin plates were sputter-coated with osmium plasma and images were obtained by SEM.

\section{RESULTS}

\section{Pg attachment on the resin plates}

The crystal violet staining showed that Pg attachment was reduced on the plates treated with the resin coating materials after incubation with Pg (Fig. 3 and 4). Two-way ANOVA revealed a significant difference in the quantitation of staining (coating materials/control; $p<0.001, \mathrm{~F}=33.22$, incubated time; $p=0.155, \mathrm{~F}=4.58$ ).
Both coating groups presented significantly lower Pg attachment compared to that of the control. No statistically significant difference was noted between the two coating materials. With regard to the incubation time, a significant difference was observed between 12 and $36 \mathrm{~h}$.

Pg shape on the resin plates

The Pg shapes on the plates treated with the resin coating materials were circular, oval and straw bag type under the SEM (Fig. 5). The Pg shapes were not different from those growing on the control resin plate, suggesting that the resin coating materials did not poison the Pg.

\section{DISCUSSION}

The quantitation of the crystal violet staining showed that the number of $\mathrm{Pg}$ attached to the plate was significantly decreased by treatment with the resin coating materials. Also, the Pg shapes were not changed by the coating, as evidenced by the detection of circular, oval, and straw bag type bacteria noted for all groups by SEM observation. It can be concluded that the resin coating materials are not harmful to $\mathrm{Pg}$. 


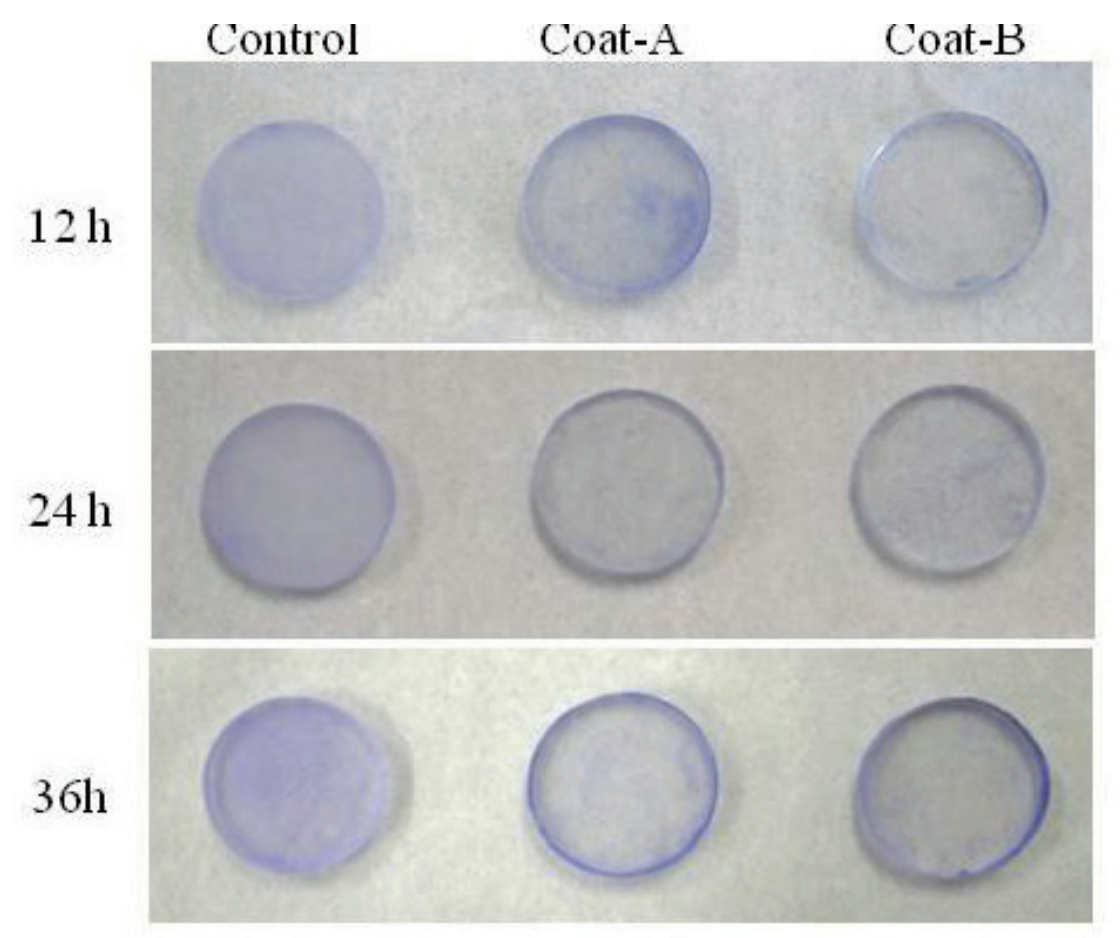

Fig. 3 Examples of stained plates.

Typical photographs of each plate stained with Crystal Violet after the plates were immersed in medium containing the Pg. The plates of control group were stained more than those of the two coating groups.

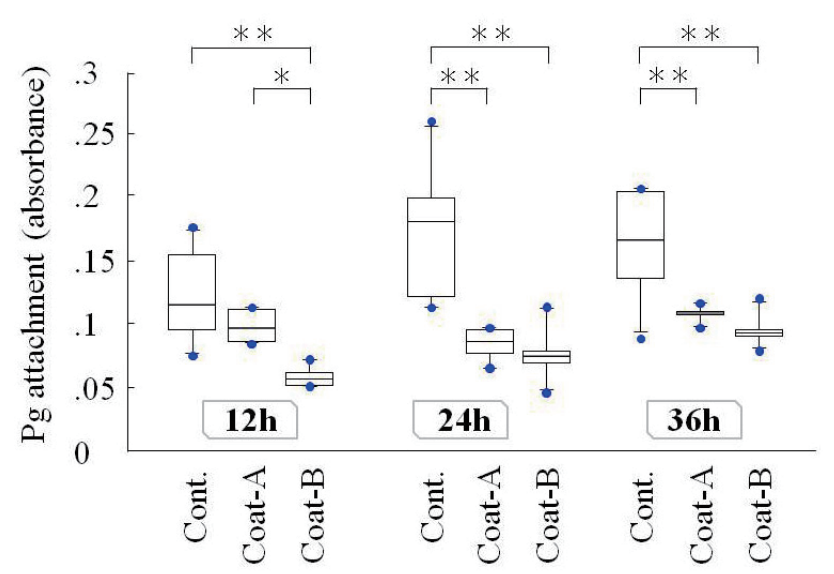

Fig. 4 Quantification of Porphyromonas gingivalis attached to the plate.

The quantification of Crystal Violet staining showed the number of $\mathrm{Pg}$ attached to the plate. The boxes represent the spreading of the data between the first and third quartiles. The central line represents the median. The whiskers denote the 5th and 95th percentiles, and dots represent the minimum and maximum values. Both coating groups presented significantly lower $\mathrm{Pg}$ attachment compared to that of the control. Two-way ANOVA and Fisher posthoc test revealed a significant difference in the quantitation of staining (coating materials/control; $p<0.001$, $\mathrm{F}=33.22$, incubated time; $p=0.155, \mathrm{~F}=4.58)$. *: $p<0.05, * *: p<0.01$.
Several factors have been studied that play a role in bacterial adhesion ${ }^{14,15)}$, and it appears that each component of the adhesion process is related to the surface characteristics of the interacting substratum and bacteria ${ }^{16,17)}$. We consider that the resin coating materials decrease the surface roughness of the resin plates, especially silica filler in Coat A and aliphatic hexaacrylate in Coat B may be the key materials for the smoothness. Physico-chemical surface components found to be involved in bacterial surface adhesion are the surface charge (zeta potential), wettability (hydrophobicity, hydrophilicity), surface free energy and surface roughness ${ }^{18-22)}$. An increased zeta potential, which refers to the electrostatic potential generated by the accumulation of ions on the surface, results in decreased bacterial attachment ${ }^{19}$ ). Wettability (contact angle) has an inverse relationship with surface free energy. It has been previously reported that the lower the contact angle, the greater the surface free energy and the adhesion to the solid surface ${ }^{23,24)}$. Moreover, the surface roughness and the surface free energy interact with each other, and the influence of the surface roughness is the dominant factor ${ }^{25}$. A rough surface in the oral cavity may predispose the surface to bacterial $\operatorname{adhesion}^{14,15)}$. Adhesion processes to solid surfaces are mainly influenced by the relative surface energy of the solid surface. Studies using Streptococcus oralis or Streptococcus mutans were reported showing that the bacterial attachment and the biofilm formation are related to the roughness of the resin surface ${ }^{26-28)}$. It is 


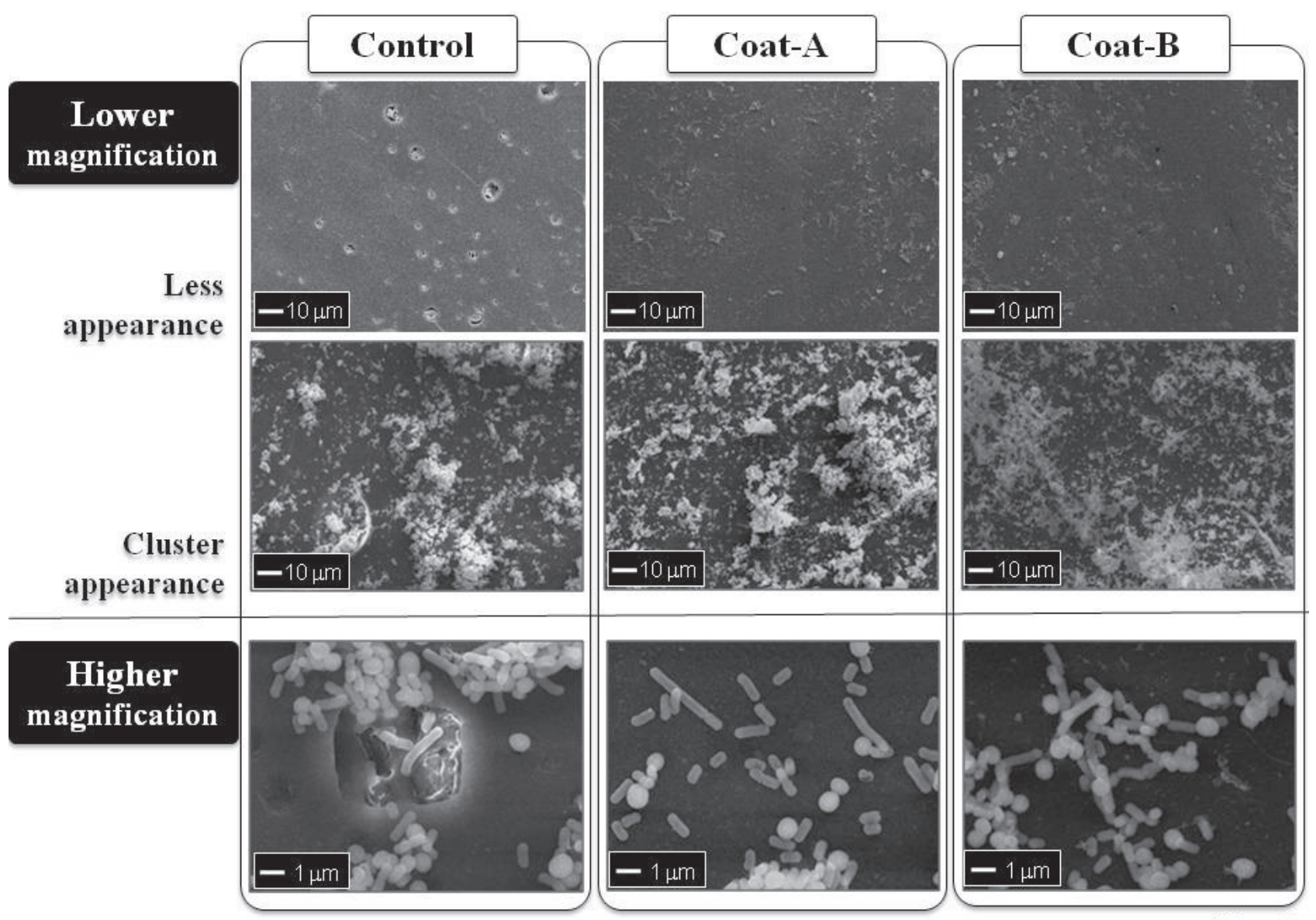

Fig. 5 SEM observation of Porphyromonas gingivalis attachment.

Each plate was immersed in the medium containing Pg for $36 \mathrm{~h}$. All groups showed a varying pattern of Pg attachment. The appearance of the attached $\mathrm{Pg}$ varied widely with the region, but was in general similar for the two coatings in the extent of attachment. In the control group, small and relatively large holes were observed on the surface. On higher magnification, the existence of $\mathrm{Pg}$ with circular, oval, and straw bag type shapes was observed. The shapes were the same in each group.

possible that smoothing the resin surface can decrease the bacterial attachment on the resin surface. The resin surface of both coating groups was glossier than that of the control group (Fig. 1), although some holes were observed on the surface of the resin under SEM observation (Fig. 5). We consider that these surface modifications by coating materials are the reason why Pg attachment was reduced.

SEM observation is especially suited for the microscopic characterization of bacterial morphology and material surfaces or the interactions between them $^{29)}$. In this study, we observed that the Pg shape did not change on the different coating materials under SEM, so that we were able to conclude that the materials are not toxic to bacteria. Both resin coating materials examined in this study have methylmethacrylate and initiators (Table 1). In addition, both coating materials contained ingredients that have already been used in the clinic and have not been reported to exert toxicity. Currently, the tendency is for the coating to prevent bacteria from accumulating rather than to kill them ${ }^{30,31)}$, the rationale being that a reduction in bacterial number will decrease the number of new and more resistant mutants. It was postulated that killing bacterium via a toxic molecule will lead to colonization by another, more resistant, bacterium, making it more difficult to eliminate the bacteria colonies.

There have been no prior investigations into whether the resin coating materials affect periodontal bacteria. In this in vitro study, we have provided the first evidence that treatment with the resin coating materials clearly prevented $\mathrm{Pg}$ accumulation on the polymerized resin plates without any toxic effect on the bacteria. However, the conditions used did not satisfactorily imitate in vivo microbial adhesion, as there was no simulation of oral shear stress or continuous saliva flow. We are planning to test the resin coating materials under human oral conditions in a future study. 


\section{CONCLUSION}

Two types of resin coating materials presented significantly lower Pg attachment compared to the control. The Pg shapes on the plates with resin coating materials were similar to the non-treated control plates. Hence, the resin coating materials clearly prevent $\mathrm{Pg}$ attachment on the polymerized auto cure resin plate.

\section{ACKNOWLEDGMENTS}

This study was partially supported by Kuraray Medical, and the company did not commit the study methods or results.

\section{REFERENCES}

1) Axelsson P, Lindhe J. Effect of controlled oral hygiene procedures on caries and periodontal disease in adults. J Clin Periodontol 1978; 5: 133-151.

2) Burke FJ, Cheung SW, Mjör IA, Wilson NH. Reasons for the placement and replacement of restorations in vocational training practices. Prim Dent Care 1999; 6: 17-20.

3) Ikai H, Kanno T, Kimura K, Sasaki K. A retrospective study of fixed dental prostheses without regular maintenance. J Prosthodont Res 2010; 54: 173-178.

4) Davidi MP, Beyth N, Sterer N, Feuerstein O, Weiss EI. Effect of liquid-polish coating on in vivo biofilm accumulation on provisional restorations: part 1. Quintessence Int 2007; 38: 591-596.

5) Hatsuno K, Mukhyama H, Horiuchi S, Iwasaki Y, Yamamoto N, Akiyoshi K, Taniguchi H. Poly (MPC-co-BMA) coating reduces the attachment of Candida albicans to poly (methyl methacrylate) surfaces. Prosthodont Res Pract 2006; 5: 21-25.

6) Hahnel S, Leyer A, Rosentritt M, Handel G, Bürgers R. Surface properties and in vitro Streptococcus mutans adhesion to self-etching adhesives. J Adhes Dent 2009; 11: 263-269

7) Eick S, Glockmann E, Brandl B, Pfister W. Adherence of Streptococcus mutans to various restorative materials in a continuous flow system. J Oral Rehabil 2004; 31: 278-285.

8) Satou J, Fukunaga A, Satou N, Shintani H, Okuda K. Streptococcal adherence on various restorative materials. J Dent Res 1988; 67: 588-591.

9) Svanberg M, Mjör IA, Orstavik D. Mutans streptococci in plaque from margins of amalgam, composite, and glassionomer restorations. J Dent Res 1990; 69: 861-864.

10) Sardin S, Morrier JJ, Benay G, Barsotti O. In vitro streptococcal adherence on prosthetic and implant materials. Interactions with physicochemical surface properties. J Oral Rehabil 2004; 31: 140-148.

11) Grivet M, Morrier JJ, Benay G, Barsotti O. Effect of hydrophobicity on in vitro streptococcal adhesion to dental alloys. J Mater Sci Mater Med 2000; 11: 637-642.

12) Luthardt RG, Stössel M, Hinz M, Vollandt R. Clinical performance and periodontal outcome of temporary crowns and fixed partial dentures: A randomized clinical trial. J Prosthet Dent 2000; 83: 32-39.

13) Zwetchkenbaum S, Weiner S, Dastane A, Vaidyanathan TK.
Effects of relining on long-term marginal stability of provisional crowns. J Prosthet Dent 1995; 73: 525-529.

14) Gibbons RJ. Adherent interactions which may affect microbial ecology in the mouth. J Dent Res 1984; 63: 378-385.

15) Mor C, Steinberg D, Dogan H, Rotstein I. Bacterial adherence to bleached surfaces of composite resin in vitro. Oral Surg Oral Med Oral Pathol Oral Radiol Endod 1998; 86: 582-586.

16) Sipahi C, Anil N, Bayramli E. The effect of acquired salivary pellicle on the surface free energy and wettability of different denture base materials. J Dent 2001; 29: 197-204.

17) Knorr SD, Combe EC, Wolff LF, Hodges JS. The surface free energy of dental gold-based materials. Dent Mater 2005; 21: 272-277.

18) Satou J, Fukunaga A, Morikawa A, Matsumae I, Satou N, Shintani H. Streptococcal adherence to uncoated and salivacoated restoratives. J Oral Rehabil 1991; 18: 421-429.

19) Weerkamp AH, Uyen HM, Busscher HJ. Effect of zeta potential and surface energy on bacterial adhesion to uncoated and saliva-coated human enamel and dentin. J Dent Res 1988; 67: 1483-1487.

20) Olsson J, van der Heijde Y, Holmberg K. Plaque formation in vivo and bacterial attachment in vitro on permanently hydrophobic and hydrophilic surfaces. Caries Res 1992; 26: 428-433.

21) Quirynen M, Marechal M, Busscher HJ, Weerkamp AH, Arends J, Darius PL, van Steenberghe D. The influence of surface free-energy on planimetric plaque growth in man. $J$ Dent Res 1989; 68: 796-799.

22) Bollen CM, Lambrechts P, Quirynen M. Comparison of surface roughness of oral hard materials to the threshold surface roughness for bacterial plaque retention: a review of the literature. Dent Mater 1997; 13: 258-269.

23) Erickson RL. Surface interactions of dentin adhesive materials. Oper Dent 1992; Suppl 5: 81-94.

24) O'Kane C, Oliver RG, Blunden RE. Surface roughness and droplet contact angle measurement of various orthodontic bonding cements Br J Orthod 1993; 20: 297-305.

25) Quirynen M. The clinical meaning of the surface roughness and the surface free energy of intra-oral hard substrata on the microbiology of the supra- and subgingival plaque: results of in vitro and in vivo experiments. J Dent 1994; 22 (Suppl 1): S13-16.

26) Morgan TD, Wilson M. The effects of surface roughness and type of denture acrylic on biofilm formation by Streptococcus oralis in a constant depth film fermentor. J Appl Microbiol 2001; 91: 47-53.

27) Beyth N, Bahir R, Matalon S, Domb AJ, Weiss EI. Streptococcus mutans biofilm changes surface-topography of resin composites. Dent Mater 2008; 24: 732-736.

28) Charman KM, Fernandez P, Loewy Z, Middleton AM. Attachment of Streptococcus oralis on acrylic substrates of varying roughness. Lett Appl Microbiol 2009; 48: 472-477.

29) An YH, Friedman RJ. Laboratory methods for studies of bacterial adhesion. J Microbiol Methods 1997; 30: 141-152.

30) Ofek I, Hasty DL, Sharon N. Anti-adhesion therapy of bacterial diseases: prospects and problems. FEMS Immunol Med Microbiol 2003; 38: 181-191.

31) Sharon N, Ofek I. Fighting infectious diseases with inhibitors of microbial adhesion to host tissues. Crit Rev Food Sci Nutr 2002; 42(3 Suppl): 267-272. 